\title{
Comunicação e gestão de crises: uma análise do gerenciamento da Petrobras durante a Operação Lava Jato*
}

\section{Communication and crisis management: an analysis of Petrobras management during Lava Jato Operation}

Danilo Almeida Silva' Luiz Claudio Ferreira ${ }^{2}$
Recebido em: 13/07/2015. Aprovado em: 22/09/2015.

1 Jornalista e especialista em gestão da comunicação nas organizações.

2 Orientador do Artigo é Mestre em Comunicação, especialista em Comunicação e Abordagem Textual e bacharel em Jornalismo. .

\section{Resumo}

Este estudo objetiva identificar erros e acertos da Petrobras na comunicação durante a crise provocada pela Operação Lava Jato. Para tanto, escolheu-se o período 12 a 15 de dezembro de 2014, em que a imprensa divulgou denúncias nas quais a então presidente da estatal, Maria das Graças Foster, teria conhecimento do desvio de milhões de reais em diretorias da organização. Analisaram-se 30 matérias publicadas nos portais G1 e UOL. As conclusões foram comparadas com as informações divulgadas no Blog Fatos e Dados, da Petrobras. Dessa forma, mediu-se o quanto o conteúdo e as informações divulgadas pela estatal influenciaram a cobertura da imprensa. Também objetivou-se identificar se a comunicação da empresa seguiu preceitos de autores sobre gerenciamento de crises. O resultado revelou que, no período analisado, as ações de comunicação da Petrobras, por meio do blog, foram ineficientes para amenizar a crise. Palavras-chave: Crise. Comunicação. Blog Fatos e Dados. Operação Lava Jato. Corrupção.

\section{Abstract}

This study aims to identify successes and failures in Petrobras communication during the crisis caused by the start of Operação Lava Jato, which reported a grand scheme of corruption involving the company. Therefore, we chose the period between 12 and 15 December 2014, in which the press published allegations that the president of the company, Maria das Graças Foster, know about million deviation schemes in organizational boards. This research analyzed the contents of 30 subjects, published in the journalistic sites G1 and UOL, which were compared with the information published in the Blog Dados e Fatos (Petrobras). This way, could be possible measure how much the information published by the institution influenced, in some way, in press coverage. The methodology of this study also aimed to identify if the company's communication followed precepts of several authors on crisis management in organizations. The result was that, in the analyzed period, Petrobras communication activities through the blog were inefficient.

Keywords: Crisis. Communication. Blog Fatos e Dados. Lava Jato Operation. Corruption. 


\section{Introdução}

O presente estudo tem como objetivo analisar o gerenciamento de crise realizado pela empresa estatal Petróleo Brasileiro S/A (Petrobras) durante a Operação Lava Jato. Uma série de fatos negativos divulgados pela imprensa, a partir de março de 2014, expôs diretorias e até a presidência da companhia em um escândalo de corrupção bilionária.

São vários os casos em que uma gestão de crise adequada pode amenizar os impactos de um evento negativo. Da mesma forma, a má administração de eventos delicados pode causar prejuízos incalculáveis à imagem. Chinem (2003, p. 86) conceitua que "qualquer situação que escape ao controle da empresa e que ganhe visibilidade pública pode ser considerada uma crise”. Em seguida, o autor prossegue e ressalta que "seja qual for a origem de uma crise, o fato é que ela pode afetar os negócios de uma empresa".

Nesse contexto, Rosa (2001, p. 23) afirma que os efeitos de uma crise de imagem atingem o patrimônio mais importante de qualquer entidade ou personalidade que mantenha laços estreitos com o público: a credibilidade, a confiabilidade, a reputação, o que se refere ao caso da empresa em estudo, uma vez que teve ações na bolsa desvalorizadas em virtude da perda de confiança por parte dos acionistas, por exemplo. Os problemas ligados à reputação nas crises são catalisados pela quantidade de notícias negativas veiculadas na imprensa. Forni (2013, p. 45), por exemplo, ao relatar os resultados de pesquisas feitas no Brasil, lembra que "[...] o peso da cobertura negativa de uma crise, na imagem de uma organização, é extremamente deletério para a reputação e, consequentemente, para os negócios".

E esses eventos extremos são fonte de conhecimento para gestores interessados em aprender com os erros e acertos de grandes e pequenas corporações na gestão dos eventos negativos. A identificação de erros e acertos da estatal brasileira no processo de comunicação, nos últimos meses, pode contribuir para este campo de estudo. Cada crise tem as suas peculiaridades e o presente trabalho objetiva identificar as deste caso e avaliar se parte da estratégia utilizada pela equipe de comunicação da companhia foi adequada.

\section{Crise de imagem e gestão de crise}

Para Rosa (2001, p. 21), atualmente as crises de imagem "se sucedem na rotina de nossas vidas, uma após a outra, variando de personagem para personagem, na dinâmica por vezes alucinante da vida real". Ou seja, tornaram-se parte do cotidiano, principalmente pela ação da mídia. O que muda são os personagens, mas sempre uma crise nova surge e "abafa" a antiga, tomando o lugar de "crise da vez".

Cabe lembrar que não há como parar ou censurar a veiculação das notícias, uma vez que a liberdade de imprensa é pressuposto essencial nas sociedades democráticas. O que se pode é aprender a conviver com os jornalistas, com o público e saber como se portar e relacionar com a mídia quando a crise chegar. Para isso, é importante estar preparado.

Nesse sentido, de acordo com Viana (2001, p. 173), é necessário construir pontes, encurtar distâncias, ou seja, se relacionar constantemente com a mídia. Assim, quando um evento negativo ocorrer, haverá uma imagem mínima construída. Isso é o que fortalece as credenciais da empresa em situações em que sua credibilidade se torna frágil ou vulnerável. E, para encurtar distâncias e lidar com os veículos de comunicação, é indispensável, quando ocorrer uma crise, a presença de um assessor para acompanhar e auxiliar o assessorado na condução do relacionamento com a mídia. Saber como se comunicar é essencial durante uma crise, pois a forma como são colocadas as versões dos fatos (isso inclui gestos, ações, palavras erradas) pode agravá-la ainda mais.

Os autores consultados destacam ainda que a gestão da crise não é responsabilidade apenas do setor de comunicação organizacional, mas de todos os dirigentes e funcionários da empresa. O pessoal da comunicação é importante nesse processo, mas se faz necessária a sensibilização dos executivos para a forma de lidar com a crise e com a imprensa. Os gestores, muitas vezes pela formação que possuem, se preocupam única e exclusivamente com os lucros e resultados, esquecendo-se do impacto que uma perda de reputação pode causar no ativo imagem.

Mesmo assim, com a gestão da crise sendo responsabilidade dos executivos da organização, o relacionamento com a mídia e a opinião pública não pode ser deixado para um momento julgado "mais oportuno". Quanto mais rápida se der a comunicação, melhor. Ainda 
mais em tempos de internet e redes sociais. Em outras palavras, "para a empresa não basta ter uma cultura de comunicação, é imperativo criar uma cultura de comunicação em tempo real. Toda a sociedade está condicionada por essa nova perspectiva" (VIANA, 2001, p. 171). E é nessa perspectiva que entram as ferramentas institucionais para a comunicação, cujas principais detalhamos a seguir.

\section{Ferramentas institucionais}

Uma frase atribuída a Abraham Maslow, psicólogo estadunidense, carrega a seguinte ideia: se a única ferramenta que alguém possui é um martelo, a pessoa tende a ver todos os problemas como um prego. Isso, claramente, seria uma limitação. Portanto, é necessário àqueles que trabalham em uma assessoria de comunicação conhecer os diversos tipos de ferramentas disponíveis para "conversar" com os vários públicos.

Uma coletiva de imprensa, por exemplo, não é o mais indicado para comunicados rotineiros, sem grandes impactos sociais ou econômicos. Às vezes, uma simples nota em um perfil de rede social, complementada por um release no portal, pode ser o suficiente. Além disso, não se deve esquecer que os colaboradores e stakeholders, como investidores e fornecedores, também são públicos estratégicos de qualquer instituição e devem ser lembrados na política de comunicação social de qualquer empresa ou governo.

Saber aplicar corretamente os diferentes produtos de uma assessoria a diferentes públicos torna a atuação estratégica e não mais operacional. Duarte (2002, p. 237) cita 34 diferentes "ferramentas" para atuar na comunicação interna e externa. Faremos um apanhado geral de algumas daquelas que consideramos serem as mais presentes na administração de crises organizacionais no Brasil, no que tange ao público externo.

A mais conhecida delas nas assessorias é o press release, ou relise na tradução. Na definição de Chinem (2003, p. 67), este seria o "texto jornalístico produzido pela área especializada com o objetivo de informar as redações sobre assuntos de interesse da organização". Kopplin e Ferraretto (2001, p. 59) explicam que, embora não seja aproveitado na íntegra pelas redações, esse material é escrito segundo os critérios jornalísticos. De acordo com eles, o relise tem por função básica levar às redações notícias que possam servir de apoio, atração ou pauta.
Outra importante ferramenta destacada pelos autores é a nota oficial. Esta pode ser definida como um "texto distribuído em situações críticas que requerem um posicionamento forte e definido do assessorado" (KOPPLIN; FERRARETTO, 2001, p. 63). A divulgação dela pode ajudar a reduzir boatos, dúvidas e pressões por informações, além de ser uma estratégia para evitar a exposição de um representante da organização, de acordo com Duarte (2002, p. 248).

Quando o uso de uma nota não for suficiente e, na avaliação da organização, o caso requerer, pode-se utilizar da entrevista coletiva no esclarecimento de fatos ou emissão de posicionamento. "Ela é um recurso importante para o assessor de imprensa, porque possibilita a divulgação de fatos e/ou opiniões relacionados ao seu cliente de uma forma dinâmica e com resultados abrangentes" (KOPPLIN; FERRARETTO, 2001, p. 104). Mas cabe lembrar que este é um recurso extraordinário e que não se deve lançar mão dessa ferramenta apenas para aparecer na mídia. Para Duarte (2002, p. 245), a função de uma coletiva deve restringir-se a situações como passar informações relevantes de interesse público, lançamentos, assinaturas de acordos, entre outros com proporções e impactos parecidos.

Ressalta-se, ainda, o treinamento específico para as fontes ou porta-vozes, também conhecido como media training. Muitas vezes, um bom executivo pode ter problemas ao lidar com uma câmera, gravador ou microfone. Somado a um ambiente tenso, cheio de jornalistas, isso pode representar um desastre para a organização. Com o objetivo de evitar situações constrangedoras, o assessor deve pensar na preparação das fontes da empresa. "O investimento em capacitação é uma das melhores maneiras de qualificar o relacionamento com a imprensa, porque ajuda a fonte a compreender e atender às necessidades do jornalista e a melhor aproveitar as oportunidades de exposição" (DUARTE, 2002, p. 253).

Outra importante estratégia consiste em manter um site permanentemente atualizado. Ele é a porta de entrada da organização e será a primeira fonte de consulta dos públicos que tenham interesse em conhecê-la melhor ou obter produtos e serviços. No caso dos jornalistas, pode-se até mesmo disponibilizar uma área específica onde possam encontrar a maior parte das informações disponíveis e os contatos da assessoria de imprensa. "Com informações confiáveis, sempre atualizadas e de fácil acesso, o site torna-se um indispensável referencial de consulta 
para qualquer um que queira obter informações sobre uma entidade ou organização" (KOPPLIN; FERRARETTO, 2001, p. 115).

Ainda tendo a internet como plataforma, existe a possibilidade do uso de blogs. Eles estão cada vez mais presentes no cotidiano das pessoas e organização e influenciam diretamente na construção da opinião pública, especialmente aqueles que são engajados em um tema específico. Pode-se falar que uma infestação blogueira modifica a visão que um público tem de uma pessoa, lugar, produto ou fenômeno (HEWITT, 2007, p. 30). Tendo em vista esse potencial, as organizações não desejam estar alheias e sim participar ativamente desse processo de construção da opinião pública. "O blog é uma oportunidade quase gratuita de estabelecer e defender uma marca, introduzir novos produtos ou produzir agitação por um tempo indefinido" (HEWITT, 2007, p. 160). O autor destaca ainda que a blogosfera é uma mídia. Muita informação circula neste âmbito. Talvez por isso, empresas como a própria Petrobras, analisada nesse trabalho, optem por criar e alimentar constantemente essa ferramenta. Desse modo, podem "controlar" de certa forma o que está sendo dito a respeito delas nos veículos tradicionais de comunicação.

\section{Recomendações para lidar com a crise}

Além de uma assessoria de imprensa, destacada no item 1, outra orientação que os autores consultados dão às empresas consiste na escolha de um porta-voz oficial adequado. Este seria responsável pelos pronunciamentos da organização em todas as entrevistas. Deve ser um profissional preparado tanto para o relacionamento com a mídia quanto em relação ao negócio da empresa. De acordo com Forni (2013, p. 220), uma das primeiras funções de uma equipe de comunicação de crise é selecionar esse porta-voz, pois nas crises as organizações precisam ter cara e devem se mostrar.

Também se destaca o que Rosa (2001, p. 118) definiu como plano de administração de crises. Ter um plano já pressupõe que a organização reconhece que terá que lidar com algum evento negativo algum dia. Este, nas palavras do autor, seria "um repertório de ações que podem e devem ser adotadas de acordo com a necessidade de cada situação". Esse repertório de ações pode envolver a hora certa de publicar uma nota, realizar uma coletiva de imprensa, divulgar informações em redes sociais, ou até mesmo alguma entrevista exclusiva. São todas ações que podem surtir efeitos positivos, se utilizadas da maneira correta.

Criar um Grupo de Administração de Crises, ou Comitê de Crise, é outro ponto destacado por autores sobre o tema para a melhor administração das crises organizacionais. Esse grupo, que constitui um núcleo de comando nas decisões relativas ao enfrentamento das crises, é constituído pelos principais executivos de áreas estratégicas da organização, podendo ou não ser coordenado pelo comandante máximo da instituição. A orientação é de que esse grupo tenha poucos integrantes, no máximo dez. Ele deve contemplar áreas-chave. $\mathrm{O}$ coordenador deve ter autonomia para a tomada de decisões, além da confiança da diretoria da organização para o comando nas situações turbulentas.

Para além das orientações já citadas, os valores que a organização deseja passar durante uma crise devem ser enfatizados nas entrevistas e em todos os tipos de pronunciamento público. Eles constituem o que autores definem como doutrina da crise. Estes valores, refletidos não apenas em palavras, mas em ações, podem ajudar a contornar a situação de forma positiva.

\section{Procedimentos metodológicos}

A metodologia aplicada foi o estudo de caso. "Tal investigação permitirá inicialmente fornecer explicações no que tange diretamente ao caso considerado e elementos que lhe marcam o contexto" (LAVILLE; DIONNE, 2008, p. 155).

Foi selecionada uma amostra de 30 matérias jornalísticas veiculadas nos portais Universo Online e Globo (G1), escolhidos em função de levantamento realizado pela empresa de informação Alexa ${ }^{3}$ que, em 2013, os indicou como, respectivamente, o $5^{\circ}$ e $6^{\circ}$ sites mais acessados do Brasil (as primeiras posições entre os veículos de caráter jornalístico). Também são analisados conteúdos veiculados, no mesmo período, no portal institucional e no Blog Fatos e Dados, da Petrobras.

As notícias selecionadas foram as 15 primeiras publicadas a partir de 12 de dezembro de 2014, que tenham citado o nome da Petrobras de alguma forma, em

\footnotetext{
Alexa é uma empresa norte-americana que, fundada em 1996, realiza pesquisas e análises sobre comportamento de usuários e mensurações relacionadas a sites na web.
} 
cada um dos portais de notícia a partir da veiculação pelo jornal Valor Econômico de que a ex-gerente executiva da Petrobras, Venina Velosa, teria alertado a ex-presidente da companhia, Maria das Graças Foster, sobre desvios de recursos em licitações de refinarias.

\subsection{Procedimento fundamental}

Foram cruzados os documentos: as notas de esclarecimento emitidas pela empresa, disponibilizadas no Blog Fatos e Dados 4 , e as reportagens sobre o assunto. Analisam-se os seguintes itens: 1) se houve aproveitamento de informações vindas da Petrobras; 2) modo como foram aproveitadas (nota na íntegra ou apenas trechos); 3) o tom da reportagem (positivo, neutro, negativo); 5) possíveis mensagens-chave que podem ser identificadas nos textos; 5) quem são as fontes ${ }^{5}$ informadas pela reportagem; 6) principal fonte da reportagem, 7) como a estatal é citada na matéria (diretamente ou para explicar o contexto da operação Lava-Jato).

Caponigro (2000 apud FORNI, 2002, p. 365) já destacava que "a decisão estratégica de como comunicar durante e depois de uma crise é uma das mais importantes decisões que você tomará na administração da crise". Por isso, com base na literatura consultada sobre crise, tentou-se identificar, nas notas publicadas pela Petrobras, os seguintes pontos: 1) quais mensagens-chave e quantas são; 2) extensão dos textos (em parágrafos); 3) se há recursos como gráficos, analogias, vídeos ou histórias para facilitar o entendimento do público; 4) se explicita ações da empresa para reverter ou prevenir situações que levaram à crise; 5) quantas notas são publicadas no período; 6) se a organização se coloca como vítima; 7) postura percebida da organização (derrotismo, preocupação ou resiliência); 8) admissão de algum possível erro.

As informações foram coletadas e tabuladas para cada um dos itens acima, de modo que a análise abordasse um número consistente de pontos referenciais para retirar a conclusão do estudo proposto neste artigo. A seguir estão as principais evidências encontradas.

4 O blog se propõe a esclarecer e tornar transparente a relação da companhia com a mídia. Endereço: <http://www.petrobras.com.br/fatos-e-dados/>.

5 "A maioria (das narrativas) contém informações fornecidas por instituições ou personagens que testemunham ou participam de eventos de interesse público. São o que se chama de fontes" (LAGE, 2009, p. 49).

\section{Análise}

\subsection{Reportagens}

As reportagens analisadas do Portal G1 foram publicadas no período entre 12 e 15 de dezembro de 2014, em área criada no site para notícias da Operação Lava Jato ${ }^{6}$. Já as do UOL foram publicadas entre 12 e 14 de dezembro também em local específico do site ${ }^{7}$. Ao verificar o primeiro item, se informações da assessoria foram aproveitadas, observa-se que houve maior espaço para a Petrobras no G1 em relação ao portal UOL, pertencente ao Grupo Folha. Foi considerada informação "aproveitada" quando houve referência ao posicionamento da empresa.

Quadro 1 - Referência ao posicionamento da empresa

\begin{tabular}{|c|c|c|}
\hline Veículo & Sim & Não \\
\hline UOL & 4 & 11 \\
\hline G1 & 6 & 8 \\
\hline TOTAL & 10 & 19 \\
\hline \multicolumn{2}{|c|}{ Fonte: do autor. }
\end{tabular}

Algumas reportagens repetiam informações de uma mesma nota, uma vez que apenas quatro textos foram publicados no site da Petrobras ao longo do período analisado. Percebe-se que apenas uma reportagem cita que a empresa não se pronunciou sobre um fato novo, mas, mesmo assim, já havia o reaproveitamento de informação de nota anterior em trecho sobre fato antigo. $\mathrm{Na}$ categoria de informações não aproveitadas, são consideradas reportagens em que não houve referência a algum posicionamento da companhia.

No G1, em seis das 15 reportagens analisadas, há ou uma nota integral publicada ao final da matéria ou trechos do posicionamento da companhia, disponibilizado no blog Fatos e Dados. Enquanto isso, nas matérias publicadas no UOL, apenas quatro textos contêm trechos do posicionamento da estatal (nenhum com nota integral). Já no G1, quatro possuem uma nota integral da empresa publicada ao final da matéria, e, em três delas, também há trechos da nota em determinados pontos do texto jornalístico. Outras duas matérias do G1 possuem apenas trechos do posicionamento oficial da empresa citados.

6 Endereço: <http://g1.globo.com/politica/operacao-lava-jato/index.html $>$.

7 Endereço: <http://noticias.uol.com.br/politica/temas/operacao-lava-jato/>. 
Quadro 2 - Forma de aproveitamento das informações da assessoria

\begin{tabular}{|c|c|c|}
\hline Veículo & Trechos da nota & Íntegra da nota \\
\hline UOL & 4 & \\
\hline G1 & 5 & 4 \\
\hline TOTAL & 9 & 4 \\
\hline
\end{tabular}

Verifica-se que não houve bom aproveitamento da versão da companhia como um todo: apenas um terço das matérias analisadas possui o posicionamento da Petrobras publicado de alguma forma (no todo ou em parte)

$\mathrm{Na}$ análise também foi verificada se a forma como a empresa está colocada na reportagem seria negativa, positiva ou neutra para a imagem institucional. Ao todo, em 26 matérias identifica-se que a Petrobras teve a imagem arranhada com as matérias (negativo). Já em três reportagens verifica-se que há, de alguma forma, enquadramento positivo para a empresa. No entanto, isso corresponde a $10 \%$ das reportagens analisadas e pode demonstrar um possível insucesso da comunicação na crise da companhia.

Quadro 3 - Tom das reportagens para a Petrobras

\begin{tabular}{|c|c|c|}
\hline Positivo & Negativo & Neutro \\
\hline 3 & 26 & 1 \\
\hline
\end{tabular}

No contexto das matérias publicadas no G1, a análise das versões da companhia permitiu identificar as seguintes mensagens-chave: apuração dos fatos (em quatro textos), punição de envolvidos (em três reportagens) e prestação de contas à sociedade (em uma matéria). Já no contexto das matérias publicadas no UOL, apenas a ideia de "apuração dos desvios" esteve presente nos quatro textos em que houve posicionamento.

Ao mesmo tempo, mensagens negativas mais enfáticas ficaram subentendidas nos textos. Em seis dos analisados, que correspondem a um quinto do total, a ideia de desleixo ou omissão da diretoria da empresa esteve presente. Além disso, em três matérias uma possível queda da então presidente da estatal, Maria das Graças Foster, esteve presente. A mensagem de apuração de desvios ou de possível punição de envolvidos pode ser identificada em dez reportagens. Outras mensagens figuram com menos ocorrência, conforme tabela abaixo.
Quadro 4 - Mensagens-chave com mais ocorrência nas matérias publicadas

\begin{tabular}{|c|c|}
\hline Mensagem principal da matéria & Quantidade de ocorrências \\
\hline Desleixo da diretoria & 6 \\
\hline Queda da presidente & 3 \\
\hline Punição dos envolvidos & 9 \\
\hline Apuração de desvios & 3 \\
\hline
\end{tabular}

Com relação às fontes citadas nas matérias, em 13 delas a própria imprensa serve como referência, o que demonstra, conforme os autores consultados, como uma crise de imagem, assim como começa, vai se retroalimentando pelos próprios veículos de comunicação. Vale lembrar que os problemas ligados à reputação nas crises são catalisados por notícias negativas veiculadas na imprensa. "O peso da cobertura negativa de uma crise, na imagem de uma organização, é extremamente deletério para a reputação e, consequentemente, para os negócios” (FORNI, 2013, p. 45).

A Petrobras, por exemplo, figura como fonte em 11 reportagens (de um total de 30 ), quantidade menor. Mas o maior destaque está por conta do Ministério Público Federal, que assumiu posição, na definição de Lage (2009), como fonte oficial para a imprensa.

Quadro 5 - Principais fontes nas matérias publicadas (com mais ocorrências)

\begin{tabular}{|c|c|}
\hline Fonte & Quantidade de ocorrências \\
\hline Ministério Público Federal & 15 \\
\hline Imprensa & 13 \\
\hline Petrobras & 11 \\
\hline Justiça Federal & 8 \\
\hline Parlamentares da oposição & 4 \\
\hline Venina Velosa & 4 \\
\hline
\end{tabular}

Ao analisar o quadro percebe-se que parlamentares da oposição ao governo federal são ouvidos em quatro matérias, número relativamente pequeno, porém com grande peso na crise vivida pela companhia, ainda mais diante de Comissões Parlamentares de Inquérito (CPIs). Assim, o veículo corre o risco de se transformar em "uma espécie de plataforma para a publicação de denúncias, subentendendo-se que qualquer denúncia interessa ao público e que, consequentemente, tem de ser publicada, a despeito da condição da denúncia” (SILVA, 2006, p. 48). 
A ideia é recorrente entre os autores sobre jornalismo. Ainda mais que alguns políticos "recorrem a todo tipo de truques, piruetas e efeitos especiais para conseguir um bom lugar diante das câmeras" (MARTINS, 2005, p. 92).

Se lembrarmos que Rosa (2001, p. 205) destaca que a crise brasileira passa necessariamente pelo Estado (políticos, órgãos e instituições públicas) e a Petrobras é uma empresa estatal, com cargos advindos de indicações políticas, pode-se verificar uma aplicação prática do conceito trazido pelo autor. Poderíamos acrescentar a essa ideia, tendo-se em vista o verificado na análise, que a crise brasileira também possui como fonte/origem quase que obrigatória, algum parlamentar ou político. Se o critério considerado na análise for o da fonte principal, em que a matéria faria a citação no lead ${ }^{8}$ ou fosse a geradora de fato novo, os dados demonstram que a Petrobras ocupa maior espaço. No entanto, o fator político e de retroalimentação da imprensa observados anteriormente se mantêm em destaque, conforme tabela a seguir.

Quadro 6 - Fontes mais presentes no lead

\begin{tabular}{|c|c|}
\hline Fonte & Quantidade de leads presente \\
\hline Petrobras & 5 \\
\hline Parlamentares da oposição & 4 \\
\hline Juiz Federal & 4 \\
\hline Imprensa & 3 \\
\hline Ministério Público Federal & 3 \\
\hline
\end{tabular}

Por último, também foi analisada nas reportagens a forma como a Petrobras figurava no texto: se diretamente citada no escândalo por meio de algum fato novo ou apenas na contextualização do caso, como ocorrem nas matérias sobre denúncias recebidas contra donos de empreiteiras, por exemplo. Em ambas, é negativo para a imagem organizacional ter o nome citado em um grande esquema de corrupção.

Quadro 7 - Forma como a estatal é citada nas matérias

\begin{tabular}{|c|c|}
\hline Diretamente & Contextualização \\
\hline 17 & 13 \\
\hline
\end{tabular}

Fonte: do autor

8 Lead é o termo utilizado no jornalismo para designar o primeiro parágrafo da notícia.

\subsection{As notas e a comunicação}

Com relação ao material publicado no Blog Fatos e Dados, verifica-se que, no mesmo período das matérias analisadas, foram publicadas somente quatro notas oficiais. Essa ferramenta de assessoria de imprensa pode ser definida como um "texto distribuído em situações críticas que requerem um posicionamento forte e definido do assessorado" (KOPPLIN; FERRARETTO, 2001, p. 63). A divulgação de notas pode ajudar a reduzir boatos, dúvidas e pressões por informações, além de ser uma estratégia para evitar a exposição de um representante da organização, de acordo com Duarte (2002, p. 248).

Em todos os textos desse tipo divulgados pela Petrobras, identificou-se que as principais mensagens-chave que a estatal tenta passar são apuração dos desvios e tomada de providências. Quanto à extensão das notas oficiais, metade possui cinco parágrafos e a outra metade quatro, em conformidade com o que os autores consultados recomendam: poucas ideias centrais com mensagens-chave fortes e claras. Além disso, as providências tomadas pela companhia são explicitadas. Em sua grande maioria, as informações não correspondem exatamente ao que a imprensa expõe nas notícias, mas contêm a mensagem de que a companhia apura os fatos.

Um dos pontos negativos ocorre quanto aos poucos recursos utilizados no blog. Não há gráficos, analogias, vídeos ou histórias para facilitar o entendimento do público. De acordo com Hewitt (2007, p. 160), o blog “é uma oportunidade quase gratuita de estabelecer e defender uma marca, introduzir novos produtos ou produzir agitação por um tempo indefinido". De acordo com o autor, esse tipo de ferramenta é cada vez mais presente no cotidiano das pessoas e organizações e influencia diretamente na construção da opinião pública, especialmente aqueles que são engajados em um tema específico.

Os textos, mesmo com cinco ou quatro parágrafos, dificilmente são lidos na íntegra ou possuem entendimento rápido e isso cansa o leitor que foi atrás do posicionamento da empresa. "Quando um executivo fala do alto de sua cadeira, cercado de subordinados, é uma coisa, mas quando ele se comunica com a sociedade é bem outra, porque o público não tem necessariamente a obrigação de ouvi-lo" (CHINEM, 2003, p. 86). A organização poderia então fazer uso de infográficos e até mesmo vídeos para prender mais atenção ou explicar melhor o posicionamento oficial. Esses recursos se somariam à nota já publicada. 
Ao verificar a correspondência entre as quatro notas publicadas no período analisado e as matérias veiculadas nos jornais, percebe-se que tentavam explicar o assunto e as denúncias. Também foram exaustivas, no sentido de expor o máximo de fatos. Desta forma, a repercussão de novos fatos é minimizada já na primeira divulgação. $\mathrm{O}$ blog citou as matérias às quais as notas se relacionavam, possibilitando ao cidadão que acessasse o posicionamento da empresa verificar a reportagem que gerou a resposta publicada.

No entanto, há ocorrência de uma matéria veiculada na imprensa em que um relatório de auditoria interna da companhia teria responsabilizado 19 pessoas por fraudes em licitações, mas, no blog da Petrobras, não há referência ao documento. Isso faz com que os cidadãos não sejam prestigiados, no sentido de obter informação no site da companhia, o que contraria a orientação de autores consultados: de que as organizações devem assumir o controle da divulgação dos fatos relacionados à crise.

A Petrobras também se utilizou apenas de notas, quando deveria tomar a frente na divulgação dos fatos e, para isso, poderia ter lançado mão de outros recursos. Em tempos de redes sociais, uma sugestão consistiria em publicar no blog e redes sociais um vídeo em que a então chefe da companhia reforçasse o posicionamento da estatal, prestando contas à sociedade. A Petrobras, todavia, esperou entrevista de Venina Velosa no Fantástico ${ }^{9}$ para, no dia seguinte, conceder entrevista sobre o caso. Mas a empresa corria atrás do prejuízo, podendo ter se antecipado.

Além disso, sempre foram publicadas apenas as notas enviadas aos veículos. Nenhum material de caráter exclusivo foi direcionado aos leitores do blog, que poderiam ser importantes difusores do posicionamento da estatal. O modo de operacionalizar as ações poderia ser diferente do que já se vinha fazendo (apenas publicar notas enviadas aos veículos).

Claro sabe-se que, neste tipo de situação, a decisão não é apenas do setor de comunicação, mas de um comitê de crise composto por representantes de várias áreas estratégicas, conforme explicado anteriormente. Caberia então a esse grupo não ficar na defensiva, que foi a postu-

9 Programa semanal exibido na Rede Globo, aos domingos à noite. A entrevista no dia seguinte foi dada pela então presidente da companhia, Maria das Graças Foster, no Jornal Nacional, da mesma emissora. ra percebida, mas tomar a frente da situação e das divulgações relativas à companhia.

Destaca-se ainda que as informações relacionadas à Operação Lava Jato ou estão dispersas no blog ou agrupadas apenas às relacionadas à CPI no Congresso Nacional. Outra sugestão seria criar um espaço da Lava Jato no blog, reafirmando a mensagem de transparência, em que a companhia disponibilizasse todas as notas e medidas tomadas relacionadas ao caso. Além disso, diminuiria o tempo gasto pelo cidadão à procura do posicionamento da Petrobras e informações favoráveis à empresa no caso.

\section{Considerações finais}

Tendo em vista as referências bibliográficas consultadas, o histórico da crise até o período analisado e as ações da companhia, pode-se concluir que a comunicação da Petrobras foi ineficiente no período de avaliação. Faltou à companhia tomar a frente da divulgação dos fatos. Claro, é uma crise grave e com desdobramentos políticos e econômicos no País e no exterior. Mas, também e justamente por isso, a credibilidade deve ser reforçada com a proatividade e a demonstração de transparência para com a sociedade.

A empresa, em determinadas situações, poderia ter se utilizado de forma mais efetiva das potencialidades da ferramenta blog e se posicionar durante a divulgação de qualquer fato relacionado à investigação da Polícia Federal e do Ministério Público Federal, podendo até mesmo se antecipar. No entanto, a estatal se mostrou muito receptiva e pouco proativa neste sentido, se valendo apenas da publicação das notas já enviadas à imprensa. Não se contesta a qualidade do material produzido e disponível no blog, que seguiu preceitos de renomados autores do gerenciamento de crise. Mas este foi o único instrumento, entre várias possibilidades.

O estudo leva a crer que a Petrobras estava refém dos acontecimentos e atuando na defensiva. Isso pode ter contribuído ainda mais para dificultar um bom posicionamento da companhia ao longo da crise. De acordo com os autores consultados neste trabalho, durante uma crise de imagem, as organizações devem ocupar a posição de protagonismo e principal fonte de informações à imprensa e à sociedade. Essa função ficou com o Ministério Pú- 
blico Federal ${ }^{10}$ e com o juiz federal Sérgio Moro, que analisa boa parte dos processos da Lava Jato. Dessa forma, a sociedade ouve menos a organização e mais outros atores, o que agrava ainda mais a crise.

Portanto, no período analisado, a Petrobras pecou por ter uma baixa atuação e poucas soluções que a permitissem estar à frente da divulgação dos acontecimentos relacionados à Operação Lava Jato, ainda mais quando o caso envolveu a própria presidente da empresa. Conclusão a que este trabalho chegou ao analisar o Blog Fatos e Dados e comparar o conteúdo lá publicado com a presença de versões da companhia em matérias veiculadas na imprensa.

\section{Referências}

CANAVILHAS, João. Webjornalismo: da pirâmide invertida à pirâmide deitada, 2006. Disponível em: <http:// www.bocc.ubi.pt/pag/canavilhas-joao-webjornalismo-piramide-invertida.pdf>. Acesso em: 07 out. 2015.

CHINEM, Rivaldo. Assessoria de imprensa: como fazer. São Paulo: Summus, 2003.

DIEGUES, Sílvia Cristina Pires. A comunicação de crise e a Web 2.0: um retrato de empresas portuguesas. 2011. 144 f. Dissertação (Mestrado) - Universidade da Beira Interior, Covilhã, 2011.

DUARTE, Jorge. Produtos e serviços de uma assessoria de imprensa. In: (Org.). Assessoria de imprensa e relacionamento com a mídia. São Paulo: Atlas, 2002.

FORNI, João José. Gestão de crises e comunicação: o que gestores e profissionais de comunicação precisam saber para enfrentar crises corporativas. São Paulo: Atlas, 2013.

HEWITT, Hugh. Blog: entenda a revolução que vai mudar seu mundo. Rio de Janeiro: T. Nelson, 2007.

KOPPLIN, Eliza; FERRARETTO, Luiz Artur. Assessoria de imprensa: teoria e prática. Porto Alegre: S. Luzzatto, 2001.

LAGE, Nilson. A reportagem: teoria e técnica de entrevista e pesquisa jornalística. Rio de Janeiro: Record, 2009.

LAVILlE, Christian; DIONE, Jean. A construção do saber. 8. reimpr. Belo Horizonte: UFMG, 2008.

10 Criou-se um hotsite com informações sobre o caso e que alcançou mais de 600 mil visualizações. Endereço: <http:// www.lavajato.mpf.mp.br/>.
MARTINS, Franklin. Jornalismo político. São Paulo: Contexto, 2005.

PENA, Felipe. Teoria do jornalismo. São Paulo: Contexto, 2005.

ROSA, Mário. A era do escândalo: lições, relatos e bastidores de quem viveu as grandes crises de imagem. São Paulo: Geração, 2003.

ROSA, Mário. A síndrome de Aquiles: como lidar com as crises de imagem. 2. ed. São Paulo: Gente, 2001.

SILVA, Juliana Américo Lourenço da. Os 50 sites mais acessados do Brasil, segundo o site Alexa. Infomoney, São Paulo, 13 nov. 2013. Disponível em: <http://www.infomoney.com.br/minhas-financas/gadgets/noticia/2961393/ sites-mais-acessados-brasil-segundo-site-alexa>. Acesso em: 29 out. 2014 .

SILVA, Luiz Martins da. Jornalismo e interesse público. In: SEABRA, Roberto; SOUSA, Vivaldo (Org.). Jornalismo político: teoria, história e técnicas. Rio de Janeiro: Record, 2006.

TRAQUINA, Nelson. O estudo do jornalismo no século XX. São Leopoldo: Unisinos, 2001.

TRAQUINA, Nelson. Teorias do jornalismo: porque as notícias são como são. 2. ed. Florianópolis: Insular, 2005.

VIANA, Francisco. De cara com a mídia: comunicação corporativa, relacionamento e cidadania. São Paulo: Negócio, 2001. 